\title{
Alternative liquid dielectrics in power transformer insulation: a review
}

\author{
Bokang Agripa Tlhabologo, Ravi Samikannu, Modisa Mosalaosi \\ Department of Electrical, Computer and Telecommunications Engineering, Botswana International University of Science \\ and Technology, Botswana
}

\section{Article Info \\ Article history: \\ Received Apr 19, 2021 \\ Revised Jun 17, 2021 \\ Accepted Jul 7, 2021 \\ Keywords: \\ Dielectric strength \\ Liquid dielectrics \\ Mineral oil \\ Natural ester \\ Power transformer}

\begin{abstract}
Transformer liquid dielectrics evolved where mineral oil has been the dominant choice until emergence of synthetic esters and natural esters. Natural ester-based oils have been under extensive investigations to enhance their properties for replacing petroleum-based mineral oil, which is nonbiodegradable and has poor dielectric properties. This paper focuses on exposition of natural ester oil application in mixed transformer liquid dielectrics. Physical, chemical, electrical, and ageing characteristics of these dielectrics and the dissolved gas analysis (DGA) were reviewed. Physical properties include viscosity, pour point, flash and fire point which are vital indicators of heat insulation and fire risk. Chemical properties considered are water content, acid number, DGA, corrosive sulphur, and sludge content to limit and detect degradation and corrosion due to oil ageing. Electrical properties including breakdown voltage were considered for consistent insulation during overload and fault conditions. These properties of evolving alternative dielectrics were reviewed based on ASTM International standards and International Electro technical Commission standards for acceptable transformer liquid dielectrics. This review paper was compiled to avail modern methodologies for both the industry and scholars, also providing the significance of using mixed dielectrics for power transformers as they are concluded to show superiority over non-mixed dielectrics.
\end{abstract}

This is an open access article under the CC BY-SA license.

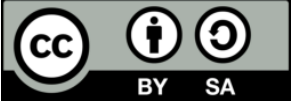

\section{Corresponding Author:}

Bokang Agripa Tlhabologo

Department of Electrical, Computer and Telecommunication Engineering

Botswana International University of Science and Technology

Private Bag 16, Palapye, Botswana

Email: bokang.tlhabologo@studentmail.biust.ac.bw

\section{NOMENCLATURE}

\begin{tabular}{ll}
\hline Nomenclature & \multicolumn{1}{c}{ Referred to } \\
\hline BDV & Breakdown Voltage \\
DBPC & Di-tertiary-butyl-paracresol \\
DGA & Dissolved gas analysis \\
DIN & Deutsches Institut für Normung \\
IEC & International Electrotechnical Commission \\
OECD & Economic Co-operation and Development \\
PD & Partial Discharge \\
TCG & Total Combustible Gas \\
TMP & Trimethylolpropane \\
UV & Ultraviolet \\
\hline
\end{tabular}




\section{INTRODUCTION}

Power transformers play a vital role in electrical power distribution to end users from power utilities. The transformer ensures that power is transmitted efficiently. Adequate cooling is necessary since there is significant heating up of the transformer core due to increased load and transient faults [1], hence the need to develop effective transformer dielectric insulators. Mineral oil has been the most commonly used dielectric due to its good electrical insulation and cooling characteristics [2]. However, concerns on the nonbiodegradability of mineral oil [3] have influenced exploration of natural esters over the years [4]. Mineral oils are further considered not environmentally friendly because they have low flash point and fire point which poses a risk of fire under surge and transient fault conditions.

Transformer dielectrics also provide electrical insulation between the core and the transformer casing even under fault conditions such as winding insulation failure. Most transformer fails are traceable to insulation failure [5]. The dielectric insulator may also fail as its insulation degrades with time (ageing) [6], hence the need to characterize the transformer oil degradation properties. To mitigate risks posed by mineral oils, natural esters are investigated to develop effective insulators that comply with regulatory standards of American standard testing and material (ASTM) and international electrotechnical commission (IEC). When considering pure esters, studies have shown that they have high viscosity [7] and their high cost of production have motivated a change of direction towards blending mineral oil and ester oil together, and further looking into mixing with nano particles to make superior nanofluids [8]. Methods used to test pure fluids can deduce their behavioural characteristics from their structures and composition. However, these cannot universally be used in testing mixed dielectrics because unlike their pure counterparts, mixed dielectrics could have different oxidation patterns. It is therefore imperative to find possible properties of esters blended with mineral oils. Different experimental and simulation methodologies have been used to analyse their properties. These include, but not limited to, ramp application, Locke method, DGA and gas chromatography, Gaussian's probability statistics analysis, Poison's statistical equation, Duval's triangle methods, partial discharge, Fourier transform analysis, broadband dielectric spectroscopy, and molecular simulation technology analysis. These methods are reviewed in detail in the other sections of this paper in their respective applications. It is therefore important to improve methods of analysing and diagnosing insulator properties before, during and after use for each proposed insulator to avoid catastrophic failure of the transformer [9].

This paper elaborates on the evolution of transformer liquid dielectric insulation as modern testing approaches are applied to them by different scholars. Furthermore, the review shows the limitations and improvements to methodologies used. There is small, consolidated literature on methods applied in mixed transformer dielectrics hence the study informs on key focal properties of dielectrics being physical, chemical, electrical, aging, and dissolved gas analysis based on previous scholarly research. These properties are expository reviewed as breakdown voltage (BDV), flash and fire point, viscosity, oxidation stability, DGA, moisture content analysis and biodegradability. It further enlightens on alternative blending of natural and mineral oil dielectrics and other miscible liquids/fluids through the application of nanoparticles in concerted efforts to find a suitable replacement for pure mineral oil. Consolidated findings are intended to recommend and guide present research and industrial production and safe utilization of more reliable mixed transformer dielectrics.

\section{EVOLUTION}

Transformer liquid dielectrics have been categorised into mineral oil, synthetic oil, ester oil, mixed and nanofluid oils as in Figure 1. The evolution of these dielectrics began with the use of mineral oil. This oil is harnessed from non-renewable natural resources; hence it is nonbiodegradable. Furthermore, the low flash and fire point of mineral oil necessitated the development of synthetic oils. To improve biodegradability of power transformer dielectrics, ester-based dielectrics were considered for investigation as potential candidates. Their potential in both pure form and when mixed with mineral oil are vital for the industry. Nanofluids have also been introduced to improve the dielectric stability of mineral and ester-based dielectrics which will be further discussed in the paper. 


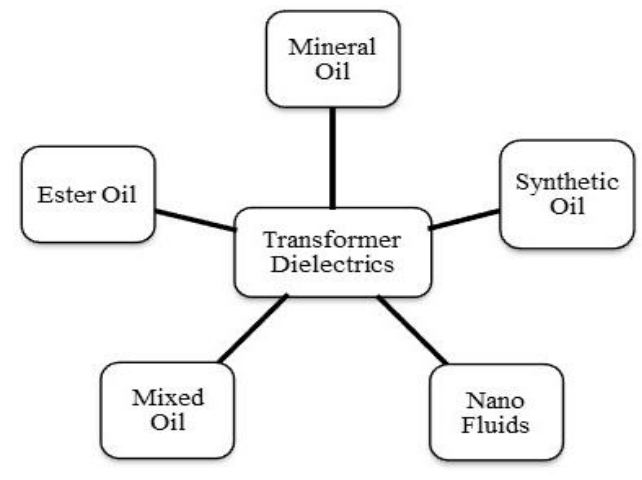

Figure 1. Categories of transformer liquid dielectrics

Natural ester oils refer to the oils extracted from cold pressing of seeds and plants [10]. The commonly used natural esters are soybean oil, sunflower oil, rapeseed oil, rice bran oil, coconut oil, corn oil, cotton seed oil, olive oil, palm nuts oil, canola oil, and pongamia pinnata oil [11], [12]. Their use in power transformers is mainly due to their electrical and chemical stability because they are made up of both saturated and unsaturated fatty acids. When an ester triglyceride is formed, alcohol glycerol forms covalent bonds with three fatty acid molecules, releasing water molecules in condensation during esterification reaction as shown in (1). This makes them less prone to oxidation. Figure 2 shows the formed fatty acid ester triglycerides with single unsaturated fatty acids which gives them advantage to be used in power transformers as the bonds of unsaturated fatty acids make the dielectric more susceptible to oxidation [13].

$$
\mathrm{R}-\mathrm{COOH}+\mathrm{HO}-\mathrm{R} \rightleftharpoons \mathrm{R}-\mathrm{COOR}^{\prime}+\mathrm{H}_{2} \mathrm{O}[14]
$$

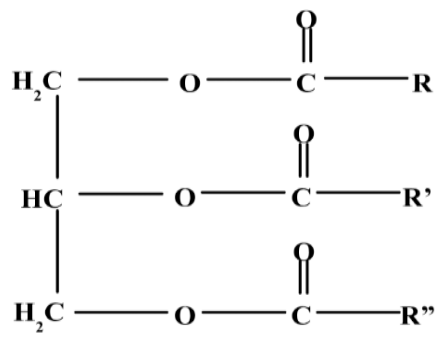

Figure 2. Fatty acid ester triglycerides with single unsaturated fatty acids [13]

\subsection{Dielectric capabilities of alternative dielectrics}

Ester based dielectrics have been highly comparable to mineral oil [15]. In 1990, Diana and Watson [16] used the ramp application technique and the experimental analysis produced comparable characteristics of ester as to mineral oil. This is in the sense that ester oil used was found to have Ohmic transport behaviour in the pre-breakdown test. This is to say there is a linear relationship of current and voltage induced during the experiment when plotted on a log-log plot. The decade 1990 to 2000 brought more research to probe the usefulness of esters in transformer insulation. Conseil international des grands reseaux electriques (CIGRE) working group [17] gave a detailed performance analysis of ester-based dielectrics. CIGRE work group found that the water solubility in natural esters is significantly higher than in mineral oil, which is a contributing factor to good dielectric strength in mineral oil. When further investigating viscosity of esters, they are found to be much more viscous than mineral oil which poses a risk of developing hotspots in the transformer tank. Another crucial property emphasised by [17] is the absence of corrosive sulphur in ester oil which greatly reduces the tendency to cause corrosion by sulphur reacting with the windings of the transformer. This is a common phenomenon with mineral oils as they contain corrosive sulphur.

\subsection{Ageing, solubility, and lifetime of dielectrics}

McShane et al. in [18] used Lockie method for aging tests beyond 500\% expected life to perform accelerated life tests in which he concluded that using esters for transformer dielectrics will ultimately increase lifetime of the solid insulator, hence an increase of transformer life span. McShane et al. [19] further

Alternative liquid dielectrics in power transformer insulation: a review (Bokang Agripa Tlhabologo) 
emphasises that the rate of aging of craft paper is associated to the liquid dielectric that it is immersed in. This shows that with mineral oil, the ageing rate is quite faster than that of natural esters. The finding concurs with [17]. This fast ageing can therefore be factored by corrosive sulphur presence and low water solubility causing acid formation in mineral oil. Smith [20] has shown that natural ester oil can be used to replace mineral oil in transformers of at least $450 \mathrm{kV}$. However, to maintain the rated temperature rise, the transformer cooling requirements should be modified to accommodate the physical property of natural esters as they are much more viscous than mineral oil. Having less viscous dielectric allows ease circulation of the oil, hence promoting cooling. This principle is further elaborated in this paper at viscosity subsection.

Darwin et al. [21] elaborated on the solubility property of esters which helps absorb any moisture content that may develop on the insulation paper in the core. However, the study on the other hand shows that when using esters alone, the cost is three to eight times the cost of using mineral oil. It is therefore important to reduce cost by having a mixed dielectric of both natural ester and mineral oil. Fofana et al. [22] compared thermal and electrical stresses of mineral and ester oils against their aging performance. In this the use of esters is recommended based on the superiority of their physical and chemical properties that promote slower degradation when ageing. Esters tend to age slower and have better moisture absorption than mineral oil which prolongs the lifetime of insulating paper.

\subsection{Mixing ratios of dielectrics}

IEEE [23] also released maintenance and acceptance standards to be used in regulating and standardising the use of esters as transformer dielectrics. It is with these standards that Ulrych et al. [24] suggests the use of mixed dielectrics made from ester and mineral oil with inhibitors for safer transformer insulation technology. Fofana et al. [25] investigated high voltage transformer mixed dielectric insulator properties. The dielectrics are a mixture of ester and mineral oil in different proportions. Like non-mixed dielectrics, the physical, chemical and electrical properties were tested. They concluded that gassing tendencies are reduced when adding ester to mineral oil under thermal stress and the general mixture has superior properties compared to pure mineral oil alone.

Gupta and Das [26], Gaussian's probability statistics method with normal and Weibull distribution is applied to study the breakdown voltage of the dielectrics. It shows that silicon as a synthetic ester has the lowest BDV followed by mineral oil then natural ester oil get the highest BDV. It is then concluded that natural esters are more suitable to use to mix with mineral oil to enhance its electrical properties based on the asymmetric Weibull distribution of breakdown voltage. Furthermore, a mixture proportion of natural ester oil and mineral oil is made taking into consideration the cost of esters which is eight times the cost of mineral oil [21]. Therefore, it is practical to use more mineral oil than ester in the mixing ratio. One limitation to the methods of mixing the oils is that there was no standard mixing ratio in place to obtain a standard mixture. Apart from their excellent electrical and chemical properties, [27] emphasises on mixing esters with mineral oil because the density and kinematic viscosity of esters are well above the standard limit provided by IEC guide.

When further discussing alternative dielectrics to mineral oils, Borsi and Gockenbach [28] concludes that the miscibility property of esters has enabled mixing with mineral oil, making a superior mixture with high BDV which minimizes the chances of transformer malfunctions. When thermal stress is applied to esters and mineral oil at different temperatures, the experimental analysis suggested a future scope of research on using inhibitors [29] with esters to extend oxidation stability and lower the dissipation factor when replacing mineral oils [30]. Karthik et al. [31] also emphasises the use of mixed dielectrics since the natural esters have shown highest BDV, flash and fire point when in an experiment that compares mineral, synthetic and natural ester oils.

When comparing characteristics of alternative dielectrics to mineral oil, Fernandez et al. [32] analysed mixtures of mineral and ester oil at various proportions to find the optimal mixing ratio. Optimality is based on having high fire resistance performance at lower cost. This implies that esters used in the blend should be volumetrically less than mineral oil for cost minimization yet improving the BDV, flash and fire point of mineral oil. Vegetable oils that have proved to be well within the standard of IEC guide for transformers include rapeseed, sunflower, canola oil and soybean [32].

\section{PROPERTIES OF TRANSFORMER LIQUID DIELECTRICS}

Methods under review are those used in BDV, flash and fire point, viscosity, oxidation stability, DGA, moisture content analysis, and biodegradability of power transformer dielectrics. Table 1 gives a summary of standard tests that are carried out for transformer dielectrics for safety and quality purposes. These standards are further elaborated on in the paper as they are explored in different studies. 
Table 1. Standard tests for transformer dielectrics

\begin{tabular}{lll}
\hline \multicolumn{1}{c}{ Property } & \multicolumn{1}{c}{ Standards } & \multicolumn{1}{c}{ Acceptable Limit } \\
\hline Breakdown Voltage & IEC 60156, 2.5 mm, 2 kV/sec Gaussian's probability statistics [2], [33]. & $>30 \mathrm{kV}$ \\
Viscosity & ASTM D445 using a CANNON-Fenske Routine Viscometer at 40 ${ }^{\circ} \mathrm{C}$ & Upper limit: $12 \mathrm{~mm}{ }^{2} / \mathrm{sec}$ \\
& {$[12]$.} & or cSt at 40 $^{\circ} \mathrm{C}$ \\
Flash and Fire Point & Pensky-Martens Closed Cup Tester with reference to ASTM D93 [12]. & $>145^{\circ} \mathrm{C}$ \\
Moisture content & IEC 60814 using Karl Fischer Coulometer instrument [34], [35]. & $<35 \mathrm{ppm}$ \\
Acid Number & ASTM D974 [12], [36]. & $<0.01 \mathrm{mg} \mathrm{KOH} / \mathrm{g}$ \\
Partial Discharge & IEC60270, Phase-resolved analysis method [37]. & - \\
\hline
\end{tabular}

\subsection{Breakdown voltage}

Breakdown voltage is the most significant parameter in transformer dielectric. Dielectric breakdown voltage is defined as the ability of the dielectric to withstand dielectric stresses. It is a measure of how much voltage it takes to produce a spark between two electrodes that are separated by some distance while immersed in the oil. The dielectric breakdown voltage test traditionally used for service aged fluids is ASTM D877. This method is less sensitive compared to ASTM D1816 for small amounts of contamination hence ASTM D1816 and IEC 60156, are the most favourable method [33]. This is because ASTM D1816 and IEC 60156 do not experience and even depend on substantial quasi-uniform voltage stress at the edges of parallel plates as ASTM D877 does because the former does not use flat plate electrodes. IEC 60156 standard from Table 1 dictates the experimental procedure. According to the standard procedure, the submerged electrodes are separated by $2.5 \mathrm{~mm}$ and voltage is applied to them at gradual increase of $2 \mathrm{kV} / \mathrm{sec}$ until a spark is visualised across the electrodes. It is most important that the oil is stirred with a magnetic stirrer to eliminate bubbles in it. This standard of testing further imposes minimum safety limit for BDV to be $30 \mathrm{kV}$ for liquid dielectrics. When dielectric strength degrades, it typically indicates that there is significant presence of moisture and polar particle contamination from external sources and/or insulation aging.

\subsubsection{Statistical analysis}

In 2013 Jing et al. [38] performed a statistical analysis on breakdown voltage of natural esters, synthetic esters and mineral oil, and concluded that the dielectric behaviour of esters is superior to that of mineral oils. However, it is without reasonable doubt that synthetic esters have comparable characteristics such as BDV that compete well with natural esters. It is the high production cost of synthetic esters that deters from using them. Jing et al. [38] developed some mobility equations and uses Laplace to solve for electric field distribution. Due to limitations of this Laplace equation-based method, it is recommended that poison equation be introduced to find the dielectric insulator's accurate electric field distribution values. Abdelmalik et al. [39] found out that natural ester impregnated paper had an average breakdown voltage $42 \%$ higher than mineral oil impregnated paper. Also, the natural ester impregnated paper showed only 5\% reduction in tensile strength test after 28 days of aging whereas that in mineral oil showed $35 \%$ reduction in tensile strength. This shows that natural esters indeed preserve the aging of kraft paper in the transformer.

\subsubsection{Gaussian probability analysis}

Perrier et al. [40] applied Gaussian's probabilities in analysis of breakdown voltage measured using IEC 60156 specifications with a gap distance of $2.5 \mathrm{~mm}$. The study also considers kinematic viscosity in investigating heat transfer, finding that high viscosity reduces ability of oil to circulate to transfer heat hence posing a risk of heat spots. Therefore, viscosity of mineral oil which is significantly low is preferable than that of esters. The methodologies further lead to a conclusion that for optimal mixing, synthetic ester should be at $20 \%$ to mineral oil used without degrading viscosity and electrostatic charging tendency of mineral oil. This yields a slower deteriorative dielectric when aging for the transformer. However, [41] experimentally shows that increasing the presence of ester in the mixture significantly enhance the dialectical strength. The palm oil ester required for optimal mixing is $50 \%$ which indicates that there is no standard optimal mixing ratio. This ratio for optimality only considers performance characteristics being enhanced dielectric breakdown and flash and fire point. Therefore, to obtain a dielectric with good performance characteristics, the ratio should be dependent on the properties of the individual dielectrics added to the mixture.

\subsection{Flash and fire point}

Flash point is the minimum temperature at which when heated, the oil forms a combustible vapour. Fire point then becomes the minimum temperature at which the vapour formed when the oil is heated continues to burn for a minimum of 5 seconds when ignited by an open flame. These properties are tested to satisfy ASTM D93 using Pensky-Martens closed cup tester as indicated in Table 1. Edible esters are fire safe and recommended as coolants and insulators hence suitable to use over mineral oils [42], [43]. This minimizes the risk of fire and explosion when the transformer heats up due to overload and faults. Raof et al. 
in [44] emphasizes on having a mixture of mineral oil and ester oil with mineral oil being less than $20 \%$ to produce a dielectric with better electrical and physical properties than typical mineral oil-based insulators. This is in consideration of contributions of each participant oil in improving dielectric performance of the blend. However, the $80 / 20$ ratio of ester/mineral oil was selected without considering the production costs involved with ester oil which is remarkably high [2] and other scholars who previously considered both cost and performance opted to rather have more mineral than ester in the various blends. When blending trimethylolpropane ester with mineral oil, a clear trend of increase in flash point and fire point with increase in ester percentage in the blended dielectric is observed [44]. This effect is due to the high molecular weight of ester oil as compared to mineral oil.

\subsection{Viscosity}

Viscosity as a measure of resistance to flow in a liquid has its implications in the cooling rate of a transformer. The oil should be able to circulate from region of high temperature to that of low temperature. Highly viscous oil will not efficiently flow to transfer the heat from its area of high concentration. Bertrand and Lauzevis [14] in an experiment observes that viscosity of oils decreases with rise in temperature and increases with decrease in temperature. Decreasing viscosity when temperature rises helps in easing up oil circulation hence promoting convectional heat transfer from the transformer coil, cooling, and reducing hotspot formation. The first factor affecting viscosity of dielectrics is molecular weight. The higher the molecular weight of a fluid the more its resistance to flow which is viscosity. When blending ester and mineral oil, the mechanical stirring causes vibration energy which then raptures the ester chain by carbon homolytic cleavage hence producing smaller molecules than that of the parent ester [45]. This explains why a blend of mineral and ester oil reduces the esters' viscosity and chances of producing hot spots in the insulation which yields a superior mixed transformer dielectric.

Kweon et al. [46] used the optical fibre sensor to measure hot spots in the transformer filled with natural ester and compared to mineral oil filled transformer. The life curve of the two is similar, however, it is notable that natural oil filled transformer always had higher hot spot temperatures, owing it to higher viscosity of natural esters. Chemical modification methods can be applied to reduce viscosity of natural esters. Ghani et al. [12] uses esterification with alcohol via hydrolysis to achieve the same. Reacting 2-ethyl1-hexanol with high oleic rapeseed also reduced kinematic viscosity significantly [14]. Raof et al. [47] also uses neopentyl glycol (NPG) in transesterification process of high oleic palm methyl ester and NPG alcohol and reduced kinematic viscosity to approximately $20 \mathrm{~mm}^{2} / \mathrm{s}$. These show that for each ester it is paramount to identify a suitable alcohol to use as a viscosity suppressant. Wilhelm et al. [48] indicates that other major factors of natural ester dielectrics aging are viscosity, acidity, and dissipation factor. It is noted that acidity varies due to hydrolysis whereas the viscosity varies with respect to oxidation in the natural ester. Perrier et al. [49] and [50] used kinematic viscosity to study the heat transfer of mixed dielectrics. Also, while investigating viscosity, DGA, and ageing performance of vegetal oil compared to mineral oil, [51] found that natural esters have $42.86 \%$ more lifetime than mineral oil when used in distribution transformers.

When evaluating kinematic viscosity of ester oils at $40{ }^{\circ} \mathrm{C}$, [52] found that viscosity remained constant, which means that viscosity is not affected by moisture content. Rather it is increased significantly by oxygen which corroborates the findings of Wilhelm et al. [53]. With further investigation on viscosity of natural esters, high viscosity has become the main reason that natural ester oils are not used alone in power transformers considering overloading conditions [54]. This evoked a further study by the same authors on varying structural placement of cooling fans to transformers. When predicting the hotspots and winding temperature in the transformer using Thermal-Hydraulic network model, three horizontal fans or five vertical fans provide $100 \%$ cooling/heat evacuation for natural ester oil filled transformer hence a structural modification to power transformers is recommended [55].

\subsection{Oxidation}

The presence of oxygen and water in transformer oils causes the process of oxidative degradation of oil. This is further influenced by presence of copper winding as copper acts as a catalyst to the process. Due to oxidation, the acid formed is corrosive to the insulating paper further shortening the lifetime of the transformer. Since the process involves free radical reaction, oxidation inhibitors such as 2,6-ditertiarybutylphenol and 2,6-di-tertiary-butyl-paracresol are used to interrupt the process. To assess oxidation stability, which is oxidation resistance of the oil, ASTM D2440 as in Table 1 is used by determining the amount of sludge or Iron-II-Sulphide/ferrous sulphur formed in the oil samples as they age.

Mineral oil is one of the contributing factors to corrosive sulphur that causes deterioration to both the conductive core and other metal parts of the transformer [56]. Furthermore, the dielectric strength of the insulation dielectric also decreases due to the corrosive sulphur presence [56]. Natural ester chemical structure has no sulphur compounds compared to petroleum based mineral oil which makes ester filled 
transformers more corrosive resistant. It is also concluded in [57] that ASTM 1275 methods DIN 51353 needed improvements as they were less sensitive to indicate sulphur presence in the oils used, thus posing a probability of false negatives of sulphur presence.

McShane [58] used food-grade additives to develop an edible-oil-based dielectric to mitigate the limitation of lower oxidation resistance found in esters than in mineral oils. However, susceptibility to oxidation and high pour point have been a great disadvantage of natural esters in application [49]. In this study, to overcome oxidation stability limitations, proper methods and oxidation inhibitors are used.

\subsection{Dissolved gas analysis}

Due to thermal stresses, transformer insulation materials breakdown and deteriorate gradually and release gases. These gases can be analysed to determine the rate of deterioration of sampled oil and predict pending or occurring faults. Martin et al. [59] and Perrier et al. [60] explain that the temperature range for generating stray gasses in ester oil is $40^{\circ} \mathrm{C}$ to $50^{\circ} \mathrm{C}$. The most notable gasses in envirotemp FR3 ester oil are hydrogen, ethane and some carbon dioxide. The studies further recommend modifications to methods used for DGA analysis. When sampling the oil for DGA, it is vital to take extra precaution that any air bubble should be extracted to prevent air from contacting the oil as it would negatively impact the precision of the measurement.

When electrical and thermal faults are induced to esters, the gasses generated are not necessarily different from those generated by mineral oil [61]. However, it is the rate at which gasses are generated in esters that is slower than that of mineral oil. This is because esters are more stable for medium temperature range thermal faults [61]. Khan et al. [62] further elaborates on the use of HYDRAN® 201R method, that it has the same response time for both ester and mineral oil. The comparison of results for DGA of oil samples from membrane port and HYDRAN® 201R readings match. Another way to detect fault gases is using Buchholz alarm which will still be effective when using ester oil. This has been proven by the impressive response time and gas quantity produced by HYDRAN® ${ }^{\circledR} 201 \mathrm{R}$ and envirotemp FR3, which maintains sensitivity in the transformer.

DGA and moisture content analysis for natural esters, synthetic esters and mineral oil, shows that natural esters have better specific gravity, and specific heat compared to mineral oil hence why natural ester provide better cooling capacity [63]. It is further observed that during thermal ageing, synthetic esters mainly yield ethylene, and it has less kraft paper degradation than mineral oil but more than ester oil. However, it is also noted and emphasised that natural esters have relatively higher viscosity. Murdiya et al. [64] used streamer comparison of mineral oil and vegetable oil. During the experiment, the DGA is used to explain gasses generated during streamer generation. Rao et al. [5] also used streamer breakdown theory and concludes that the presence of cellulose promotes streamer initiation more in mineral oil-based dielectric than natural ester-based dielectric. This greatly reduce BDV of mineral oil. DGA has been conducted on the evolution of fault gasses when the oil is exposed to thermal stress. It is concluded that fault gases produced in natural ester-based insulator are of significantly small quantity compared to mineral oil which indicates that ester oils are more stable hence their high fire resistance [65].

\subsubsection{Gas chromatography}

When investigating effects of heating on transformer oils, [66] uses gas chromatograph HP 6890 aided with automatic liquid sampler HP 7649. The findings of the experiment show that Hydrogen, Carbon Dioxide, Propane, Nitrogen, and Butene are the only combustible gases present in treated Refined Ricinus Oil (ester) with a total of amount of $2.9 \mathrm{ppm}$. Having few combustible gasses and at low quantities for that matter gives the dielectric its high flash and fire point. DGA is used to identify gas quantities to assess the risk of oil burning. To interpret DGA, a more precise method called total combustible gas is used. TCG results show that methyl ester oils are very much compliant to IEEE guide that set the limit for condition 1 to 720 ppm [67].

\subsubsection{Duval's triangle methods}

Perrier et al. [60] further employs Duval's triangle 1 method for low energy discharges in ester and mineral oils. Hydrogen and Acetylene gasses are discovered in the same ratios for standard grade Naphthenic mineral oil and Triester oil. For low thermal faults, natural ester oils generate mainly Hydrogen and Ethane which are more detectible by Duval's triangle 4. For mineral oils, Duval's triangle 6 is the most recommended because it has been specifically introduced to interpret ester oil DGAs. Since esters have more stray gassing than mineral oil [68] this technique that is more sensitive to stray gases by Duval triangle 6 was developed.

Gomez et al. 2014 [52] also investigated DGA in esters. Overheating fault was simulated at $150{ }^{\circ} \mathrm{C}$ while flat-plate electrode method was used in generating discharges. After discharge, the oil samples were 
collected for DGA, and Duval triangle method used to interpret the fault gasses in the sample. The results concur with those of [60] as more methane is produced in mineral oil than FR3 ester which is mostly associated to faults or defects occurring at low temperature. As a result, recommending the use of natural ester-based dielectrics and employing Duval triangle method because it is more sensitive to the straying gasses that are generated in esters during faults and defects. Duval's triangle as a graphical method is easy, more sensitive much precise to detect fault gasses [69].

\subsubsection{Partial discharge}

Muhamad et al. [70] carried out a comparative investigation on DGA and partial discharge (PD) for shell diala MX mineral oil and envirotemp FR3 ester-based transformer dielectrics in transformer fault diagnosis. The investigation considers three common transformer faults being low energy PD, overheating and high energy arching for both dielectrics with and without solid insulator and at different moisture levels. PD is carried out using IEC 60270 standards by the phase-resolved analysis method. When using the chromatography to analyse fault gases generated, PD phase resolved patterns turned up to be similar for both mineral and ester dielectrics. As a result, it is concluded that the same standards used for mineral oil to interpret PDs can be used for esters to distinguish fault types. Even though the pattern prints are similar, ester-based oil produced less gases in volumetric quantity for PD fault. It is also worth noting that the presence of solid insulator enhances generation of dissolved hydrocarbon gases in oil.

When investigating DGA in FR3 and camellia based natural ester dielectrics, [71] and [72] demonstrates that DGA methods based on relative fault gas ratios are more accurate over those based on amount of generated gas. This is because when using relative fault ratio, the test specimen is sampled from bulk oil but not from the point where breakdown occurs. The $30 \mathrm{ml}$ of oil sample is heated, and $5 \mathrm{~L}$ of oil is added in DGA together with the $30 \mathrm{ml}$ specimen. This gives room for ambiguity and less accuracy. Since natural esters and mineral oil have different molecular structures, then when using traditional three-ratio method on ester oils, the less precise method may not give a full representation of all the gasses generated during breakdown or fault occurrence. Therefore, traditional three-ratio method used in mineral oils are subject to amendment for application on ester-based dielectrics.

Wang et al. [73] studied the gasses generated in natural oil and found that the main gases generated in esters are Hydrogen and Acetylene. This concurs with the finding that conventional interpretation of PD diagnosis is applicable to natural esters. Also, [74] used statistical analysis on PD patterns of ester-based dielectrics considering skewness, mean value of shape parameter (Beta) of the Weibull function and the ratio between number of positive and negative PD. The results showed a lower PD activity in natural ester-based dielectrics in comparison to mineral oil. Esters are recommended for use in transformer oils while a further study on their viscosity is also emphasized.

\subsubsection{Needle plane method}

Subject to needle-plane electrode voltage of $28 \mathrm{kV}$, DGA of Canola-based dielectric with influence of creepage discharge shows a high generation of hydrogen and other gases compared to mineral oil. Though the IEC 60599 standards and Duval's triangle have been able to identify creepage discharge pattern for Canola-based dielectric, the standards ought to be modified to clearly analyse the dissolved gases considering creepage discharge [75]. In November 2014, IEEE [76] provided standards to be used for interpretation and analysis of fault gases in ester-based dielectrics for transformers.

Amalanathan et al. [77] performed turbidity, alternating current (AC) and direct current (DC) impulse and UV absorption spectrum tests on edible natural ester oil and thermally aged ester oil. The study concludes that indeed conditions of the transformer insulation can be monitored in real time using fluorescence analysis. This method involves using a beam of light focused on a filter onto a detector so as to identify and measure the electrons in the molecule sample that will be excited by the beam and caused to light. This helps identify the PD behaviour of the dielectric when subjected to thermal ageing.

\subsection{Moisture content}

Presence of moisture content in the dielectric compromises its dielectric strength. Since transformer temperature fluctuates, when it cools down, moisture dissolved therein becomes free molecules which degrades the fluid and cellulose-based paper and lowers insulation potential. The use of ester-based dielectric prolongs the lifespan of kraft paper significantly compared to using the convectional mineral oil [78]. This is also due to the ability of natural ester to protect the craft paper from accumulating moisture. Both studies by Rapp et al. [79] and Prevost [80] concurred that it is due to the high-water affinity of esters that moisture is absorbed by the ester hence reducing the paper ageing and degradation. 


\subsubsection{Effect of moisture content on ageing and kraft paper}

Perkasa et al. [81] used visual and Karl-Fischer titration to investigate the bubbles and water content in mineral oil and vegetable oil. Since vegetable oil is found to be more dense than mineral oil used in the study, the difference in height between the top windings and top oil level which determines hydrostatic pressure that the oil exerts on the winding surfaces determines bubble formation. This is a cause for higher hotspots formation closer to the winding hence more likelihood of bubble formation in vegetable oil-based dielectric than in mineral oil. For a wet insulation paper system, due to presence of moisture, there is lesser likelihood of bubble formation in vegetable oil-based dielectric than in mineral oil due to the higher bubble inception temperatures. The study further emphasises that on a different note, viscosity of ester-based dielectric is higher than that of mineral oil even though it decreases with time and temperature rise. The presence of moisture content also contributes to the increase in acid number in the dielectric when aging [82]. However, the natural ester oils have higher degree of polymerization than mineral oil therefore, the acid formed in ester-based dielectrics is less corrosive to the cellulose insulation [83].

In 2015, Suwarno and Marbun [84] evaluated the effect of thermal aging on mixed dielectrics. The study applied the IEC 60156 standard stated in Table 1 at $2 \mathrm{kV} / \mathrm{sec}$ rise rate for BDV using liquid dielectric test set LD60 and Megger KF875 Karl Fischer test set for moisture content analysis. In the methodology, accelerated aging is performed for 20,40 , and 60 days for temperatures $120^{\circ} \mathrm{C}$ and $150^{\circ} \mathrm{C}$ in an oven. When aging, gasses generated according to DGAs include Hydrogen and these gases with free radicals forming water molecules. This increases the moisture content in the samples in the first 20 days which momentarily decreases BDV. However, after 20 days a decrease in water content is noted which is caused by significant hydrolysis due to extended heating period. Therefore, the presence of ester oil in the mixture improves water absorption and increase aging time and BDV of the power transformer dielectric. It is further concluded in a 2020 study [85] that natural ester oil impregnated pressboard possesses $20 \%$ more breakdown strength than that with mineral oil dielectric.

\subsubsection{Impacts of heating and use of additives on moisture content}

In 2018, Beldjilali et al. [86] investigated physicochemical and isothermal charging currents of mixed vegetable olive-based oil and naphthenic mineral oil. Free water is pre-eliminated by heating the oil samples independently, at $40{ }^{\circ} \mathrm{C}$ for 40 minutes for vegetable oil and $70{ }^{\circ} \mathrm{C}$ for 60 minutes for mineral oil. The two samples are mixed at 10 different mixing ratios. The mixing is done at 800 turns/min for 30 minutes using a magnetic stirring rod so that the mixture is dissolved and miscible. Moisture content is investigated using Karl Fischer titration immediately after agitation. For more accuracy three samples are taken from the mixing bottle and their mean value considered. This accounts for the probability of non-homogeneity of the mixture. With these methods, it is concluded that with $15 \%$ of mixture being vegetable oil, all physical properties of mineral oil are improved most optimally despite esters having high moisture content. This further emphasises that there is no standard mixing ratio [87] suggests that the more effective way to eliminate free water from the two sample is by heating them at $100^{\circ} \mathrm{C}$ for both mineral and vegetable oil because the boiling point of water is $100{ }^{\circ} \mathrm{C}$ hence will be able to vaporise the water content.

In 2020, Trnka et al. [88] uses broadband dielectric spectroscopy to investigate polarization effect of paper-natural esters in the presence of $0.53 \%$ Butylated Hydroxytoluene (2,6-ditertiary-butylparacresol and Aluminium oxide $\left(\mathrm{Al}_{2} \mathrm{O}_{3}\right)$. It is found that water content increases significantly in the paper-natural ester subjected to thermal ageing. The Increase in water content is due to hydrolysis influenced by the presence of ester.

\subsection{Biodegradability}

Since existing mineral oil is non-biodegradable, further studies have been undertaken to investigate the potential of ester oils usage for power transformer applications. Sindhuja et al. [89] applies OECD 301 B standards for biodegradability, OECD 201 standards for effects of the oil on micro algae growth, OECD 202 standards for effect towards daphnids and OECD 203 standards for mortality measure on fish. The tests are performed on new and aged natural ester-based dielectrics and the results showed that ester oils have no toxic effects on living organisms. Figure 3 shows the biodegradability rates of the different oils [2], [90].

Pure natural esters show $99 \%$ biodegradability followed by synthetic esters at $80 \%$. Biodegradability of mineral oil is at $30 \%$ while silicone oil has been found to be 5\% biodegradable [2]. This makes mineral oil and silicon oil to be highly dangerous to any form of life around the transformer especially in case of oil spillages.

Biodegradability and non-toxicity of natural esters makes them less harmful to the environment [91]. The reaction products (low $\mathrm{CO}_{2}$, low corrosive sulphur, low $\mathrm{CO}$ emission and biodegradable when spilt to the ground) formed due to thermal aging are of less risk hence the focus can be shifted towards defining the optimal combination and additive quantities to increase mixed dielectric biodegradability and improve 
oxidation stability. Due to their biodegradable property, natural ester dielectrics can replace mineral oil especially in transformers near underground bodies [92].

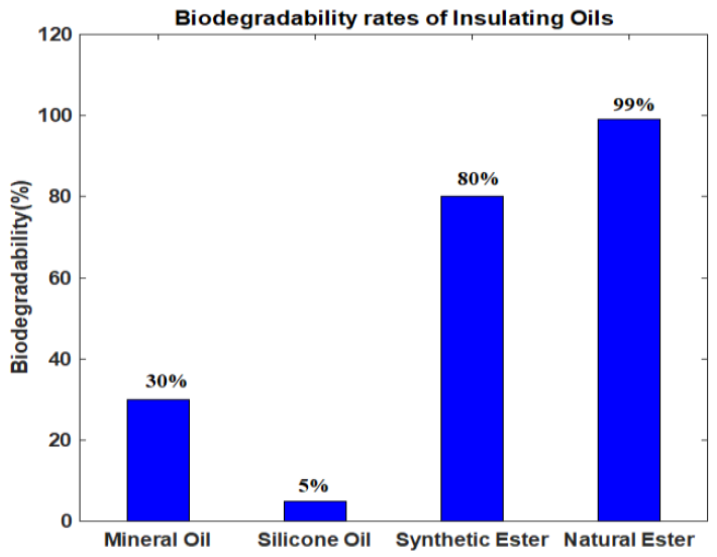

Figure 3. The biodegradability rates of mineral, silicone, synthetic ester and natural ester oils [2]

\section{MISCIBLE STUDIES}

\subsection{Use of nano particles}

Studies have proceeded to further explore the use of mixed dielectrics with multiple metal oxide Nano particles preferably those with higher stability and simpler production techniques [93]. The method of using Nanoparticles involves suspension of nanoparticles into the base transformer fluid. Such Nano particles of consideration include Iron (III) Oxide $\left(\mathrm{Fe}_{2} \mathrm{O}_{3}\right), \mathrm{Al}_{2} \mathrm{O}_{3}$, Titanium Dioxide $\left(\mathrm{TiO}_{2}\right)$, Copper (II) Oxide $(\mathrm{CuO})$, Boron Nitride (BN), Zinc Oxide ( $\mathrm{ZnO})$, Copper Peroxide $\left(\mathrm{CuO}_{2}\right)$, and Silicon Dioxide $\left(\mathrm{SiO}_{2}\right)$. It is also considered that they vary in conductivity and permittivity. It is more suitable to use Nano particles that do not agglomerate. This is to say that their particles do not form micro and macro sized attachments to one another. Two methods of preparing nanofluid dielectrics are 1) one-step method and 2) two step method.

\subsubsection{One-step method}

For one-step method, synthesis dispersion into the oil is carried out at the same time by the processes of physical vapor condensation to minimise agglomeration and enhance uniform particle distribution. The method also eliminates transportation and drying stages in the production line costs [94]. However, this process requires very sophisticated equipment which significantly increases production costs. Another limitation is that it becomes expensive to evaluate the effect of nanoparticles in the fluid because it requires elimination of impurities and residues that accumulate as a result of incomplete reaction and stabilization during synthesis [95].

\subsubsection{Two-step method}

This method involves physical and chemical methods of synthesising dried powdered nanoparticles as an initial stage. The powdered nanoparticles are at another stage dispersed or suspended into the fluid aided by ultrasonic or magnetic stirring using sonication procedure. The method is deemed more economical compared to one-stage method [95].

The most common method to assess nanofluid stability is using visual examination and light scattering techniques. In exploration of natural ester-based nanofluids as dielectrics, [96] uses statistical analysis for lightning impulse voltage for natural and synthetic ester oils-based $\mathrm{Fe}_{3} \mathrm{O}_{4}, \mathrm{Al}_{2} \mathrm{O}_{3}$, and $\mathrm{SiO}_{2}$ Nanofluids. It recommends the use of natural ester-based Nano fluids for liquid filled transformers.

Another nanofluid developed composes of hexagon nitride (h-BN) nanoparticles and cottonseed oil. The presence of h-BN enhanced impulse BDV and AC-BDV with 5\% and 63.3\%, respectively. However, as percentage weight increases the dissipation factor decreased, nonetheless, this nanofluid dielectric has great potential to be used to withstand electrical and thermal stresses in power transformers [97].

When using extrapolation in comparison of mineral oil with superior insulation fluid made of Baobab, Mongongo (as natural esters) and mineral oils under thermal aging, a blend of $5 \mathrm{ml}$ Kerosene and $100 \mathrm{ml}$ of oil under ultrasonic wave treatment at $30 \mathrm{kHz}$ reduced the rate of degradation, increasing the lifetime of copper plate and the kraft paper [8]. Even though nanofluid dielectrics have been found to have 
improved anti-aging, BDV and particle discharge characteristics [98], [99], adding nanofluids to dielectrics has its limitations too. Limitations:

- Addition of more particles increases oil viscosity.

- Nanofluids have low specific heat capacity.

- Also, the high cost of producing Nano fluids limits their use in large scale.

- They also have a lowered stability after long-term ageing due to the tendency to form micro and macro sized agglomerates. This further limit the ability to extend ageing procedural experiment of mixed dielectrics to be employed for nanofluids.

\subsection{Simulations}

Current studies are also using simulation to study flow dynamics, thermal efficiency, electric field strength, and heat transfer properties. These computational flow simulations are single-phase approach and two-phase approach [100]. Single-phase model has Buongiorno model as the most effective method over the Thermal Dispersion model and Homogenous model [93], [101]. As for two-phase model [102], [103] use Eulerian-Lagrange model and the Eulerian-Eulerian models. Karimir et al. [104] also considers particle aggregation in simulation modelling of nanofluid heat transfer. This is a comprehensive and conclusive development in studying the possible use of nanofluids for transformer dielectrics. This technique has been employed in studying diffusion behaviour of water molecules in oil and cellulose. The simulation shows that indeed water molecules are bound to cellulose in the paper insulator. This is because cellulose and water molecules can form hydrogen bonds [105].

Computerised technology has further brought evolution of molecular simulation technology application to transformer dielectrics. Molecular simulation methodologies enable scholars to analyse microphysical processes that take place in dielectrics at a micro level, yet they cannot be observable in physical experimental studies. The four main methods of molecular simulation under current studies are: molecular mechanics method, quantum mechanics method, the molecular Monte Carlo method, and the molecular dynamics method [106].

\subsubsection{Molecular mechanics method}

The method involves calculations that produce the system energy as a function of location and type of the particles' nucleus. The potential energy becomes the force field as the simulation does not take into consideration electron movement. Simulation is based on the principle that the molecular structure's relative potential energy in the dielectric is to some degree depicted by the internal stress [106].

\subsubsection{Quantum mechanics method}

This method deals with applying computerized algorithms in calculating micro-parameters of a new single tiny molecule with specific kinetic energy at $0{ }^{\circ} \mathrm{C}$ in a vacuum [106]. Computerised modelling tends to be expensive and time consuming, however with development of high-speed computers reduces the time tied expense of computation. The method gets to circumvent the expensive modelling. Quantum mechanics method provides potentially highly accurate free energy simulations by restraining potentials and thus allowing customizable shape for quantum mechanics region for molecules with high binding affinity.

\subsubsection{Molecular Monte Carlo method}

This method uses statistics analytical experimental methods to solve complex and multi-dimensional factors in a simpler manner. It mathematically develops probability model for specified characteristics of a given problem. It then runs numerical simulation experiment algorithms based on the probability model to output the approximated solution [106], [107].

\subsubsection{Molecular dynamics method}

This method calculates a good approximation of balance and transfer properties in a system of microscopic molecules as it considers a molecule as a research object. The rest of the system simulated is taken as a group of particles that exhibit specific properties or characteristics. This simulation evaluates the movement law and basic characteristics and rules of the molecule and the system at large [106]. This method has been used by [108] when investigating the restraint effect and diffusion of water. It is concluded that as simulated oil temperature increases there is a gradual increase in water diffusion.

Ruijin et al. [108] also used the molecular dynamic method in simulating the molecular model of function of furfural molecules' radial distribution considering the diffusion coefficient with different moisture content in the oil. The study concludes that furfural and small molecule acids experience a significant reduction in diffusion ability when water content increases. This molecular simulation is more optimal to study viscosity of nanofluids using amorphous modelling tool. Viscosity of the dielectric can be 
simulated from Einstein's formula whereas diffusion coefficient was obtained from using the root mean square displacement [109]. Application of the different molecular simulations can be used in enhancing microstructures of the dielectrics in accordance to predicted needs for nanofluid dielectrics.

\section{CONCLUSION}

The paper provides an overview and direction of evolution of transformer liquid dielectrics and the possible applications of mixed dielectrics. The main challenge in application of natural esters in power transformers is high viscosity. Therefore, it is recommended that mixing natural esters with mineral oil is to be used to lower the viscosity in potential dielectrics. Future use of viscosity suppressants and additives is also feasible to reduce the high viscosity. Furthermore, mixing esters and mineral oil helps improve the physical, chemical, electrical, aging, and dissolved gasses characteristics of current mineral oil-based insulation fluids. The use of technical standards for developing insulating fluids in experimental analysis of mixed dielectrics provides platform for safer development of insulating liquids. Statistical analysis methods have also shown great potential in the evolution to predict and analyse potential mixed transformer dielectrics and justifying their superior fire safety, insulation, and ageing characteristics. With statistical analysis, it is viable to design reliability functions in future to detect the survival and hazard of mixed liquid insulators and also determine their lower and upper extremities. Mixing ratios for mixed insulating dielectrics should be studied further as future scope for optimization of liquid dielectrics. Mixed liquid dielectrics also show great capability to replace pure mineral oil when simulated, analysed by chemical molecular modelling and modified at a molecular level which can hardly be achieved when doing physical experiments.

\section{REFERENCES}

[1] R. Seemamahannop, K. Bilyeu, Y. He, S. Kapila, V. Tumiatti, and M. Pompili, "Assessment of Oxidative Stability and Physical Properties of High Oleic Natural Esters," 2019 IEEE 20th International Conference on Dielectric Liquids (ICDL), 2019, pp. 1-6, doi: 10.1109/ICDL.2019.8796627.

[2] M. Rafiq, et al., "Use of vegetable oils as transformer oils-a review," Renewable and Sustainable Energy Reviews, vol. 52, pp. 308-324, December 2015, doi: 10.1016/j.rser.2015.07.032.

[3] R. G. Miller and S. R. Sorrell, "The future of oil supply," Phylosophical translations. Series A, Mathematical physics, and engineering sciences, vol. 372, pp. 1-27, 2013, doi: 10.1098/rsta.2013.0179.

[4] I. Fofana, "50 years in the development of insulating liquids," in IEEE Electrical Insulation Magazine, vol. 29, no. 5, pp. 13-25, September-October 2013, doi: 10.1109/MEI.2013.6585853.

[5] U. M. Rao, et al., "A review on pre-breakdown phenomena in ester fluids: Prepared by the international study group of IEEE DEIS liquid dielectrics technical committee," in IEEE Transactions on Dielectrics and Electrical Insulation, vol. 27, no. 5, pp. 1546-1560, Oct. 2020, doi: 10.1109/TDEI.2020.008765..

[6] Y. Hadjadj, I. Fofana, J. Sabau, and E. Briosso, "Assessing insulating oil degradation by means of turbidity and UV/VIS spectrophotometry measurements," in IEEE Transactions on Dielectrics and Electrical Insulation, vol. 22, no. 5, pp. 2653-2660, October 2015, doi: 10.1109/TDEI.2015.005111.

[7] J. Rouabeh, L. M'barki, A. Hammami I. Jallouli, and A. Driss, "Studies of different types of insulating oils and their mixtures as an alternative to mineral oil for cooling power transformers," Heliyon, vol. 5, no. 3, p. e01159, March 2019, doi: 10.1016/j.heliyon.2019.e01159.

[8] R. A. Raj, R. Samikannu, A. Yahya, and M. Mosalaosi, "Comparison of Ageing Characteristics of Superior Insulating Fluids With Mineral Oil for Power Transformer Application," in IEEE Access, vol. 8, pp. 141111141122, 2020, doi: 10.1109/ACCESS.2020.3012988.

[9] M. S. Taneja, K. Pandey, and S. Sehrawat, "A review on prognosis and diagnosis of transformer oil quality using intelligent techniques based on dissolved gas analysis," 2016 7th India International Conference on Power Electronics (IICPE), 2016, pp. 1-6, doi: 10.1109/IICPE.2016.8079419.

[10] T. Mariprasath and V. Kirubakaran, "A critical review on the characteristics of alternating liquid dielectrics and feasibility study on pongamia pinnata oil as liquid dielectrics," Renewable and Sustainable Energy Reviews, vol. 65, pp. 784-799, November 2016, doi: 10.1016/j.rser.2016.07.036.

[11] R. A. Raj, R. Samikannu, A. Yahya, and M. Mosalaosi, "An Overview of Potential Liquid Insulation in Power Transformer," International Journal on Energy Conversion (I.R.E.CON.), vol. 8, no. 4, pp. 126-140, 2020, doi: 10.15866/irecon.v8i4.19213.

[12] S. A. Ghani, N. A. Muhamad, Z. A. Noorden, H. Zainuddin, N. A Bakarb, and M.A. Talib, "Methods for improving the workability of natural ester insulating oils in power transformer applications: A review," Electric Power Systems Research, vol. 163, no. B, pp. 655-667, October 2018, doi: 10.1016/j.epsr.2017.10.008.

[13] R. Asano and S. A. Page, "Reducing Environmental Impact and Improving Safety and Performance of Power Transformers With Natural Ester Dielectric Insulating Fluids," in IEEE Transactions on Industry Applications, vol. 50, no. 1, pp. 134-141, Jan.-Feb. 2014, doi: 10.1109/TIA.2013.2269532.

[14] Y. Bertrand and P. Lauzevis, "Development of a low viscosity insulating liquidbased on natural esters for distribution transformers," in 22nd Int. Conf. Exhib.Electr. Distrib. (CIRED 2013), 2013, doi: 10.1049/cp.2013.0701. 
[15] D. K. Mahanta, "Green Transformer Oil: A Review," 2020 IEEE International Conference on Environment and Electrical Engineering and 2020 IEEE Industrial and Commercial Power Systems Europe (EEEIC/I\&CPS Europe), 2020, pp. 1-6, doi: 10.1109/EEEIC/ICPSEurope49358.2020.9160654.

[16] D. H. Ren and A. Watson, "Prebreakdown phenomena in organic ester transformer fluid," IEEE International Symposium on Electrical Insulation, 1990, pp. 57-60, doi: 10.1109/ELINSL.1990.109707.

[17] G. Cigrè, "Experiences in service with new insulating liquids," Cigre Group, vol. 35, 2010.

[18] C. P. McShane, G. A. Gauger, and J. Luksich, "Fire resistant natural ester dielectric fluid and novel insulation system for its use," 1999 IEEE Transmission and Distribution Conference (Cat. No. 99CH36333), 1999, pp. 890894 vol.2, doi: 10.1109/TDC.1999.756167.

[19] C. P. McShane, J. L. Corkran, K. J. Rapp, and J. Luksich, "Aging of paper insulation retrofilled with natural ester dielectric fluid," 2003 Annual Report Conference on Electrical Insulation and Dielectric Phenomena, 2003, pp. 124-127, doi: 10.1109/CEIDP.2003.1254810.

[20] Smith, "Design and Test Experience with Natural Ester Fluid for Power Transformers," 2005/2006 IEEE/PES Transmission and Distribution Conference and Exhibition, 2006, pp. 35-36, doi: 10.1109/TDC.2006.1668449.

[21] C. Darwin and P. Folliot, "The use of natural ester fluids in transformers," in Proc. Matpost conference, 2007.

[22] I. Fofana, J. S. N'cho, J. C. Olivares-Galvan, R. Escarela-Perez, and P. S. Georgilakis, "Comparative studies of the stabilities to oxidation and electrical discharge between ester fluids and transformer oils," 2011 North American Power Symposium, 2011, pp. 1-4, doi: 10.1109/NAPS.2011.6024859.

[23] IEEE, "IEEE Guide for Acceptance and Maintenance of Natural Ester Fluids in Transformers," IEEE standard C57.147-2008, New York, NY, 2008.

[24] J. Ulrych, M. Svoboda, R. Polanský, and J. Pihera, "Dielectric analysis of vegetable and mineral oils," 2014 IEEE 18th International Conference on Dielectric Liquids (ICDL), 2014, pp. 1-4, doi: 10.1109/ICDL.2014.6893085.

[25] I. Fofana, V. Wasserberg, H. Borsi, and E. Gockenbach, "Challenge of mixed insulating liquids for use in highvoltage transformers.1. Investigation of mixed liquids," in IEEE Electrical Insulation Magazine, vol. 18, no. 3, pp. 18-31, May-June 2002, doi: 10.1109/MEI.2002.1014964.

[26] H. Gupta and S. Das, "Statistical analysis of oil insulation breakdown voltage," 2017 IEEE International Conference on Industrial Engineering and Engineering Management (IEEM), 2017, pp. 2044-2048, doi: 10.1109/IEEM.2017.8290251.

[27] Z. Nadolny and G. Dombek, "Thermal properties of mixtures of mineral oil and natural ester in terms of their application in the transformer," in E3S Web of Conferences, vol. 19, p. 01040, 2017, doi: 10.1051/e3sconf/20171901040.

[28] H. Borsi and E. Gockenbach, "Properties of ester liquid midel 7131 as an alternative liquid to mineral oil for transformers," IEEE International Conference on Dielectric Liquids, 2005. ICDL 2005., 2005, pp. 377-380, doi: 10.1109/ICDL.2005.1490104.

[29] E. Gockenbach and H. Borsi, "Natural and Synthetic Ester Liquids as alternative to mineral oil for power transformers," 2008 Annual Report Conference on Electrical Insulation and Dielectric Phenomena, 2008, pp. 521-524, doi: 10.1109/CEIDP.2008.4772928.

[30] P. Trnka, A. Čejková, V. Mentlík, P. Totzauer, L. Harvánek, and T. Tomášková, "Effect of inhibitors on thermal degradation of vegetable oils," 2016 17th International Scientific Conference on Electric Power Engineering (EPE), 2016, pp. 1-4, doi: 10.1109/EPE.2016.7521752.

[31] R. Karthik, T. S. R. Raja, S. S.Shunmugam, and T. Sudhakar, "Performance Evaluation of Ester Oil and Mixed Insulating Fluids," Journal of Institute of Engineers, vol. 93, no. 3, pp. 173-178, 2012, doi: 10.1007/s40031-0120027-7.

[32] I. Fernández, A. Ortiz, F. Delgado, C. renedo, and S. Perez, "Comparative evaluation of alternative fluids for power transformers," Electric Power Systems Research, Elsevier, vol. 98, pp. 58-69, May 2013, doi: 10.1016/j.epsr.2013.01.007.

[33] ASTM D877, "Standard Test Method for Dielectric Breakdown Voltage of Insulating Liquids Using Disk Electrodes," ASTM International, West Conshohocken, USA, 2015.

[34] I. I. Liquids, "Oil-Impregnated Paper and Pressboard," Determination of Water by Automatic Coulometric Karl Fishcher Titration," International Electrotechnical Comission, Geneva, Switzerland, 1997.

[35] V. G. Arakelian and I. Fofana, "Water in oil-filled high-voltage equipment part II: water content as physicochemical tools for insulation condition diagnostic," in IEEE Electrical Insulation Magazine, vol. 23, no. 5, pp. 15-24, Sept.-Oct. 2007, doi: 10.1109/MEI.2007.4318270.

[36] H. Yu, R. Chen, X. Hu, X. Xu, and Y. Xu, "Dielectric and physicochemical properties of mineral and vegetable oils mixtures," 2017 IEEE 19th International Conference on Dielectric Liquids (ICDL), 2017, pp. 1-4, doi: 10.1109/ICDL.2017.8124697.

[37] A. J. Reid, M. D. Judd, R. A. Fouracre, B. G. Stewart, and D. M. Hepburn, "Simultaneous measurement of partial discharges using IEC60270 and radio-frequency techniques," in IEEE Transactions on Dielectrics and Electrical Insulation, vol. 18, no. 2, pp. 444-455, April 2011, doi: 10.1109/TDEI.2011.5739448.

[38] Y. Jing, et al., "Dielectric properties of natural ester, synthetic ester midel 7131 and mineral oil diala D," in IEEE Transactions on Dielectrics and Electrical Insulation, vol. 21, no. 2, pp. 644-652, April 2014, doi: 10.1109/TDEI.2013.003917.

[39] A. A. Abdelmalik, J. C. Fothergill, and S. J. Dodd, "Aging of Kraft paper insulation in natural ester dielectric fluid," 2013 IEEE International Conference on Solid Dielectrics (ICSD), 2013, pp. 541-544, doi: 10.1109/ICSD.2013.6619678. 
[40] C. Perrier, A. Beroual, and J.-.Bessede, "Improvement of power transformers by using mixtures of mineral oil with synthetic esters," in IEEE Transactions on Dielectrics and Electrical Insulation, vol. 13, no. 3, pp. 556-564, June 2006, doi: 10.1109/TDEI.2006.1657968.

[41] Suwarno and I. S. Darma, "Dielectric properties of mixtures between mineral oil and natural ester," 2008 International Symposium on Electrical Insulating Materials (ISEIM 2008), 2008, pp. 514-517, doi: 10.1109/ISEIM.2008.4664471.

[42] C. McShane, "New safety dielectric coolants for distribution and power transformers," in IEEE Industry Applications Magazine, vol. 6, no. 3, pp. 24-32, May-June 2000, doi: 10.1109/2943.838037.

[43] E. Gockenbach and H. Borsi, "Performance and new application of ester liquids," Proceedings of 2002 IEEE 14th International Conference on Dielectric Liquids. ICDL 2002 (Cat. No.02CH37319), 2002, pp. 203-206, doi: 10.1109/ICDL.2002.1022730.

[44] N. A. Raof, R. Yunus, U. Rashid, N. Azis, and Z. Yaakub, "Effects of palm-based trimethylolpropane ester/mineral oil blending on dielectric properties and oxidative stability of transformer insulating liquid," in IEEE Transactions on Dielectrics and Electrical Insulation, vol. 26, no. 6, pp. 1771-1778, Dec. 2019, doi: 10.1109/TDEI.2019.008128.

[45] B. Garcia, T. Garcia, V. Primo, J. C. Burgos, and D. Urquiza, "Studying the loss of life of natural-ester-filled transformer insulation: impact of moisture on the aging rate of paper," in IEEE Electrical Insulation Magazine, vol. 33, no. 1, pp. 15-23, January-February 2017, doi: 10.1109/MEI.2017.7804312.

[46] D. Kweon, K. Koo, J. Woo, and Y. Kim, "Hot spot temperature for $154 \mathrm{kV}$ transformer filled with mineral oil and natural ester fluid," in IEEE Transactions on Dielectrics and Electrical Insulation, vol. 19, no. 3, pp. 10131020, June 2012, doi: 10.1109/TDEI.2012.6215107.

[47] N. A. Raof, U. Rashid, R. Yunus, N. Azis, and Z. Yaakub, "Development of palm-based neopentyl glycol diester as dielectric fluid and its thermal aging performance," in IEEE Transactions on Dielectrics and Electrical Insulation, vol. 23, no. 4, pp. 2051-2058, August 2016, doi: 10.1109/TDEI.2016.7556478.

[48] H. M. Wilhelm, L. Tulio, R. Jasinski, and G. Almeida, "Aging markers for in-service natural ester-based insulating fluids," in IEEE Transactions on Dielectrics and Electrical Insulation, vol. 18, no. 3, pp. 714-719, June 2011, doi: 10.1109/TDEI.2011.5931057.

[49] C. Perrier, A. Beroual, and J. -. Bessede, "Experimental investigations on different insulating liquids and mixtures for power transformers," Conference Record of the 2004 IEEE International Symposium on Electrical Insulation, 2004, pp. 237-240, doi: 10.1109/ELINSL.2004.1380540.

[50] K. S. Kassi, M. I. Farinas, I. Fofana, and C. Vola, " Analysis of Aged Oil on the Cooling of Power Transformers from Computational Fluid Dynamics and Experimental Measurements," Journal of Applied Fluid Mechanics, vol. 9, no. 2, pp. 235-243, 2016, doi: 10.36884/jafm.9.SI2.25830.

[51] A. R. Marulanda, M. A. Artigas, A. Gavidia, F. Labarca, and N. Paz, "Study of the vegetal oil as a substitute for mineral oils in distribution transformer," 2008 IEEE/PES Transmission and Distribution Conference and Exposition: Latin America, 2008, pp. 1-6, doi: 10.1109/TDC-LA.2008.4641781.

[52] N. A. Gómez, H. M. Wilhelm, C. C. Santos, and G. B. Stocco, "Dissolved gas analysis (DGA) of natural ester insulating fluids with different chemical compositions," in IEEE Transactions on Dielectrics and Electrical Insulation, vol. 21, no. 3, pp. 1071-1078, June 2014, doi: 10.1109/TDEI.2014.6832250.

[53] H. M. Wilhelm, V. Franch, L. Tulio and A. F. Franch, " Compatibility of transformer construction materials with natural ester-based insulating fluids," in IEEE Transactions on Dielectrics and Electrical Insulation, vol. 22, no. 5, pp. 2703-2708, October 2015, doi: 10.1109/TDEI.2015.004755.

[54] J. Velandy, A. Garg, and C. S. Narasimhan, "Prediction of Static Pressure Drop, Velocity and Flow Rate of Higher Viscous Nature of Ester Oil in Power Transformers under Oil Directed Cooling Conditions, " 2020 IEEE 9th Power India International Conference (PIICON), 2020, pp. 1-8, doi: 10.1109/PIICON49524.2020.9112920.

[55] J. Velandy, A. Garg, and C. S. Narasimhan, "Thermal Performance of Ester Oil Transformers with Different Placement of Cooling Fan," 2020 IEEE 9th Power India International Conference (PIICON), 2020, pp. 1-7, doi: 10.1109/PIICON49524.2020.9112958.

[56] L. R. Lewand, "The role of corrosive sulfur in transformers and transformer oil," in Proceedings of the SixtyNinth Annual International Conference of Doble Clients, 2002.

[57] K. J. Rapp, A. W. Lemm, L. A. Orozco, and C. P. McShane, "Corrosive sulfur phenomena mitigation by using natural ester dielectric fluids-field experience in Latin America," 2008 IEEE/PES Transmission and Distribution Conference and Exposition: Latin America, 2008, pp. 1-6, doi: 10.1109/TDC-LA.2008.4641707.

[58] C. P. McShane, "Relative properties of the new combustion-resist vegetable-oil-based dielectric coolants for distribution and power transformers," in IEEE Transactions on Industry Applications, vol. 37, no. 4, pp. 1132 1139, July-Aug. 2001, doi: 10.1109/28.936406.

[59] D. Martin, N. Lelekakis, V. Davydov, and Y. Odarenko, "Preliminary results for dissolved gas levels in a vegetable oil-filled power transformer," in IEEE Electrical Insulation Magazine, vol. 26, no. 5, pp. 41-48, September-October 2010, doi: 10.1109/MEI.2010.5585007.

[60] C. Perrier, M. Marugan, and A. Beroual, "DGA comparison between ester and mineral oils," in IEEE Transactions on Dielectrics and Electrical Insulation, vol. 19, no. 5, pp. 1609-1614, October 2012, doi: 10.1109/TDEI.2012.6311507.

[61] Imad-U-Khan, Z. Wang, I. Cotton, and S. Northcote, "Dissolved gas analysis of alternative fluids for power transformers," in IEEE Electrical Insulation Magazine, vol. 23, no. 5, pp. 5-14, Sept.-Oct. 2007, doi: 10.1109/MEI.2007.4318269. 
[62] I. Khan, Z. Wang, J. Dai, I. Cotton, and S. Northcote, "Fault gas generation in ester-based transformer fluids and dissolved gas analysis (DGA)," 2008 International Conference on Condition Monitoring and Diagnosis, 2008, pp. 909-913, doi: 10.1109/CMD.2008.4580431.

[63] M. Augusta, G. Martins, and A.R.Gomes, "Comparative study of the thermal degradation of synthetic and natural esters and mineral oil: effect of oil type in the thermal degradation of insulating kraft paper," IEEE Electrical Insulation Magazine, vol. 28, no. 2, pp. 22-28, 2012, doi: 10.1109/MEI.2012.6159178.

[64] F. Murdiya, R. Hanaoka, H. Akiyama, K. Miyagi, K. Takamoto, and T. Kano, "Creeping discharge developing on vegetable-based oil / pressboard interface under AC voltage," in IEEE Transactions on Dielectrics and Electrical Insulation, vol. 21, no. 5, pp. 2102-2110, Oct. 2014, doi: 10.1109/TDEI.2014.004569.

[65] Z. Wang, X. Yi, J. Huang, J. V. Hinshaw, and J. Noakhes, "Fault gas generation in natural-ester fluid under localized thermal faults," in IEEE Electrical Insulation Magazine, vol. 28, no. 6, pp. 45-56, Nov.-Dec. 2012, doi: 10.1109/MEI.2012.6340524.

[66] Suwarno, M. Ilyas, and Rubadi, "Effects of temperature on dielectric properties of rhicinnus oils as insulating liquid," 2008 International Conference on Condition Monitoring and Diagnosis, 2008, pp. 286-289, doi: 10.1109/CMD.2008.4580283.

[67] "IEEE Guide for the Interpretation of Gases Generated in Mineral Oil-Immersed Transformers," in IEEE Std C57.104-2019 (Revision of IEEE Std C57.104-2008), pp. 1-98, Nov. 2019, doi: 10.1109/IEEESTD.2019.8890040.

[68] W. G. Cigre, "DGA in Non-Mineral Oils and and Improved DGA Diagnosis Criteria," Technical Brochure, 2010, p. 443.

[69] A. Akbari, A. Setayeshmehr, H. Borsi, and E. Gockenbach, "A Software Implementation of the Duval Triangle Method," Conference Record of the 2008 IEEE International Symposium on Electrical Insulation, 2008, pp. 124127, doi: 10.1109/ELINSL.2008.4570294.

[70] N. A. Muhamad, B. T. Phung, and T. R. Blackburn, "Application of common transformers faults diagnosis methods on biodegradable oil-filled transformers," Electrical Engineering, Springer, vol. 94, pp. 207-216, 2012 , doi: 10.1007/s00202-012-0232-z.

[71] Y. Liu, J. Li, and Z. Zhang, "Gases dissolved in natural ester fluids under thermal faults in transformers," 2012 IEEE International Symposium on Electrical Insulation, 2012, pp. 223-226, doi: 10.1109/ELINSL.2012.6251462.

[72] Y. Liu, J. Li, and Z. Zhang, "Fault gases dissolved in vegetable insulating oil under electrical faults," 2013 Annual Report Conference on Electrical Insulation and Dielectric Phenomena, 2013, pp. 198-201, doi: 10.1109/CEIDP.2013.6748121.

[73] Z. Wang, X. Wang, X. Yi, S. Li, and J. V. Hinshaw, "Gas generation in natural ester and mineral oil under partial discharge and sparking faults," in IEEE Electrical Insulation Magazine, vol. 29, no. 5, pp. 62-70, SeptemberOctober 2013, doi: 10.1109/MEI.2013.6585858.

[74] S. Chandrasekar and G. C. Montanari, "Analysis of partial discharge characteristics of natural esters as dielectric fluid for electric power apparatus applications," in IEEE Transactions on Dielectrics and Electrical Insulation, vol. 21, no. 3, pp. 1251-1259, June 2014, doi: 10.1109/TDEI.2014.6832272.

[75] H. Mnisi and C. Nyamupangedengu, "Dissolved Gases Analysis of canola-based ester oil under creepage discharge," 2020 International SAUPEC/RobMech/PRASA Conference, 2020, pp. 1-6, doi: 10.1109/SAUPEC/RobMech/PRASA48453.2020.9041045.

[76] "IEEE Guide for Interpretation of Gases Generated in Natural Ester and Synthetic Ester-Immersed Transformers," in IEEE Std C57.155-2014, pp.1-52, 28 Nov. 2014, doi: 10.1109/IEEESTD.2014.6966710.

[77] A. J. Amalanathan, R. Sarathi, S. Prakash, A. K. Mishra, R. Gautam, and R. Vinu, "Investigation on thermally aged natural ester oil for realtime monitoring and analysis of transformer insulation," IET High Voltage, vol. 5, no. 2, pp. 209-217, April 2020, doi: 10.1049/hve.2019.0178.

[78] C. P. McShane, K. J. Rapp, J. L. Corkran, G. A. Gauger, and J. Luksich, "Aging of Kraft paper in natural ester dielectric fluid," Proceedings of 2002 IEEE 14th International Conference on Dielectric Liquids. ICDL 2002 (Cat. No.02CH37319), 2002, pp. 173-177, doi: 10.1109/ICDL.2002.1022722.

[79] K. J. Rapp, C. P. McShane, and J. Luksich, "Interaction mechanisms of natural ester dielectric fluid and Kraft paper," IEEE International Conference on Dielectric Liquids, 2005. ICDL 2005., 2005, pp. 393-396, doi: 10.1109/ICDL.2005.1490108.

[80] T. A. Prevost, "Dielectric Properties of Natural Esters and their Influence on Transformer Insulation System Design and Performance," in Proc. IEEE Transmission and Distribution Conference and Exhibition, 2006, doi: 10.1109/TDC.2006.1668448.

[81] C. Y. Perkasa, N. Lelekakis, T. Czaszejko, J. Wijaya, and D. Martin, "A comparison of the formation of bubbles and water droplets in vegetable and mineral oil impregnated transformer paper," in IEEE Transactions on Dielectrics and Electrical Insulation, vol. 21, no. 5, pp. 2111-2118, Oct. 2014, doi: 10.1109/TDEI.2014.004493.

[82] J. Xiang, J. Li, and Z. Zhang, "Influence of water content on the aging performance of natural ester-paper insulation," 2012 International Conference on High Voltage Engineering and Application, 2012, pp. 663-666, doi: 10.1109/ICHVE.2012.6357106.

[83] M. Coulibaly, C. Perrier, M. Marugan, and A. Beroual, "Aging behavior of cellulosic materials in presence of mineral oil and ester liquids under various conditions," in IEEE Transactions on Dielectrics and Electrical Insulation, vol. 20, no. 6, pp. 1971-1976, December 2013, doi: 10.1109/TDEI.2013.6678843.

[84] Suwarno and J. Marbun, "Effect of thermal aging on the dielectric properties of mixture between mineral oil and natural ester," TENCON 2015-2015 IEEE Region 10 Conference, 2015, pp. 1-5, doi: 10.1109/TENCON.2015.7372866. 
[85] B. Ndlovu and C. Nyamupngedengu, "Investigating the Effects of Creepage Discharges on the Breakdown Voltage of Natural Ester Oil Impregnated Pressboard in Power Transformers," 2020 International SAUPEC/RobMech/PRASA Conference, $\quad 2020, \quad$ pp. $1-5, \quad$ doi: 10.1109/SAUPEC/RobMech/PRASA48453.2020.9040954.

[86] A. BeIdjilali, O. Idir, N. Saidi-Amroun, M. Saidi, and H. Moulai, "Electrical and physicochemical properties and transient charging currents in mineral and vegetable oils mixtures," in IEEE Transactions on Dielectrics and Electrical Insulation, vol. 25, no. 5, pp. 1739-1748, Oct. 2018, doi: 10.1109/TDEI.2018.007150.

[87] A. Raymon and R. Karthik, "Reclaiming aged transformer oil with activated bentonite and enhancing reclaimed and fresh transformer oils with antioxidants," in IEEE Transactions on Dielectrics and Electrical Insulation, vol. 22, no. 1, pp. 548-555, Feb. 2015, doi: 10.1109/TDEI.2014.004094

[88] P. Trnka, J. Hornak, P. Prosr, O. Michal and F. Wang, "Various Aging Processes in a Paper-Natural Ester Insulation System in the Presence of Copper and Moisture," in IEEE Access, vol. 8, pp. 61989-61998, 2020, doi: 10.1109/ACCESS.2020.2983907.

[89] K. Sindhuja, M. Srinivasan, and N.Niveditha, "Natural esters as an alternative to mineral oil in transformer applications," International Journal of Pure and Applied Mathematics, vol. 118, no. 20, pp. 723-732, 2018.

[90] V. Sarfi, S. Mohajeryami, and A. Majzoobi, "Estimation of water content in a power transformer using moisture dynamic measurement of its oil," IET High Voltage, vol. 2, no. 1, pp. 11-16, January 2017, doi: 10.1049/hve.2016.0075.

[91] Y. Bertrand and L. C. Hoang, "Vegetal oils as substitute for mineral oils," Proceedings of the 7th International Conference on Properties and Applications of Dielectric Materials (Cat. No.03CH37417), 2003, pp. 491-494 vol.2, doi: 10.1109/ICPADM.2003.1218460.

[92] P. Thomas, "Biodegradable dielectric liquids for transformer applications," Proceedings of 2005 International Symposium on Electrical Insulating Materials, 2005. (ISEIM 2005)., vol. 1, pp. 135-136, 2005, doi: 10.1109/ISEIM.2005.193350.

[93] J. Jacob, P. Preetha, and S. T. Krishnan, "Review on natural ester and nanofluids as an environmental friendly alternative to transformer mineral oil," IET Nanodielectrics, vol. 3, no. 2, pp. 33-43, 2020, doi: 10.1049/ietnde.2019.0038.

[94] V. A. Primo, B. García, and J. C. Burgos, "Applicability of nanodielectric fluids to the improvement of transformer insulation properties," 2016 IEEE International Conference on Dielectrics (ICD), 2016, pp. 76-79, doi: 10.1109/ICD.2016.7547547.

[95] D. Amin, R. Walvekar, M. Khalid, M. Vaka, N. M. Mubarak, and T. C. S. M. Gupta, "Recent Progress and Challenges in Transformer Oil Nanofluid Development: A Review on Thermal and Electrical Properties," in IEEE Access, vol. 7, pp. 151422-151438, 2019, doi: 10.1109/ACCESS.2019.2946633.

[96] A. Beroual and U. Khaled, "Statistical Investigation of Lightning Impulse Breakdown Voltage of Natural and Synthetic Ester Oils-Based Fe3O4, Al2O3 and SiO2 Nanofluids," in IEEE Access, vol. 8, pp. 112615-112623, 2020, doi: 10.1109/ACCESS.2020.3003246.

[97] R. A. Farade, et al., "Investigation of the Dielectric and Thermal Properties of Non-Edible Cottonseed Oil by Infusing h-BN Nanoparticles," in IEEE Access, vol. 8, pp. 76204-76217, 2020, doi: 10.1109/ACCESS.2020.2989356.

[98] J. E. Contreras, E. A. Rodriguez, and J. Taha-Tijerina, "Nanotechnology applications for electrical transformersA review," Electric Power Systems Research, vol. 143, pp. 573-584, February 2017, doi: 10.1016/j.epsr.2016.10.058.

[99] M. Rafiq, Y. Lv, and C. Li, "A review on properties, opportunities, and challenges of transformer oil-based nanofluids," Journal of Nanomaterials, vol. 4, pp. 1-23, 2016, doi: 10.1155/2016/8371560.

[100] W. Guan, et al., "Finite Element Modeling of Heat Transfer in a Nanofluid Filled Transformer," in IEEE Transactions on Magnetics, vol. 50, no. 2, pp. 253-256, February 2014, doi: 10.1109/TMAG.2013.2279479.

[101] Y. Zhang, S. Ho, W. Fu, X. Yang, and H. Wu, "Numerical Study on Natural Convective Heat Transfer of Nanofluids in Disc-Type Transformer Windings," in IEEE Access, vol. 7, pp. 51267-51275, 2019, doi: 10.1109/ACCESS.2019.2911712.

[102] O. Mahian, et al., "Recent advances in modeling and simulation of nanofluid flows-part I: fundamentals and theory," Physics Reports, elsevier, vol. 790, pp. 1-48, February 2019, doi: 10.1016/j.physrep.2018.11.004.

[103] M. R. Safaei, et al., "Mathematical modeling for nanofluids simulation: a review of the latest works," Akbar, N.S. (Ed.): 'Modeling and simulation in engineering sciences' (InTech, 2016), 2016, pp. 189-220, doi: 10.5772/64154.

[104] Y. Karimir, A. R. S. Nazar, and M. Motevasel, "CFD simulation of nanofluid heat transfer considering the aggregation of nanoparticles in population balance model," Journal of Thermal Analysis and Calorimetry, vol. 143, no. 1, pp. 671-684, 2021, doi: 10.1007/s10973-019-09218-0.

[105] R. J. Liao, M. Z. Zhu, X. Zhou, L. J. Yang, J. M. Yan, and C.X. Sun, "Molecular Dynamics Simulation of the Diffusion Behavior of Water Molecules in Oil and Cellulose Composite Media," Acta Physico-Chimica Sinica, vol. 27, no. 4, pp. 815-824, April 2011, doi: 10.3866/PKU.WHXB20110341.

[106] X. Xiao, W. Yang, L. Li, T. Zhong, and X. Zhang, "Application of molecular simulation in transformer oil-paper insulation," The Journal of Engineering, vol. 19, no. 16, p. 1324-1327, October 2018, doi: 10.1049/joe.2018.8875.

[107] Z. Changqing, Y. Hong, and Z. Huijun, "Molecular simulation methods and materials studio applications to polymer materials," Journal Plastics, vol. 39, no. 4, pp. 81-84, 2007. 
[108] R. J. Liao, H. G. Sun, J. Gong, W. Li, and J. G. Yin, "Ageing kinetic model and lifetime model of oil-paper insulation in transformers," Journal High Voltage Technique, vol. 37, no. 07, pp. 1576-1583, July 2011.

[109] L. Yang, J. Dai, M. Dong and L. Wang, "Molecular dynamics simulation of temperature impact on the viscosity of transformer oil-based nanofluids," 2016 International Conference on Condition Monitoring and Diagnosis (CMD), 2016, pp. 376-379, doi: 10.1109/CMD.2016.7757896.

\section{BIOGRAPHIES OF AUTHORS}
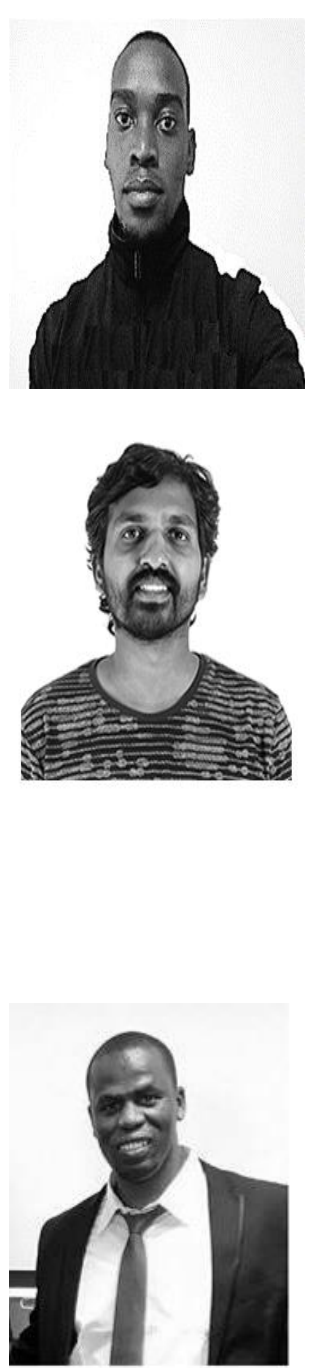

Bokang Agripa Thabologo received his Bachelor of Engineering in Electrical and Electronics in the year 2020 from the Botswana International University of Science and Technology. He is currently a scholar doing MEng in Electrical and Electronics Engineering in Botswana International University of Science and Technology. His research interests include high voltage insulation, green power technologies and solar systems design.

Ravi Samikannu is currently working as an Associate Professor, Electrical Engineering Department in Botswana International University of Science and Technology, Palapye, Botswana. Ravi Samikannu obtained his Ph.D. Degree in Electrical Engineering, from Anna University, Chennai, India. He has a total teaching experience of 14 years at undergraduate and postgraduate levels. He has published 60 research papers in International Journals. He has presented 50 papers in International and National Conferences and has received the Best Paper Award two times for his presentation. He is presently working on research projects in Big Data, Cyber Security, Internet of things, Smart Grid. He is actively engaged in teaching, research, and academic administration. He has played a major role in setting up the various laboratories for different electrical engineering courses and prepared the department for accreditation from different quality agencies like NBA, AICTE, and UGC. He is a life member of IE(I), ISTE and IEEE. He has conducted a 4 National Level Symposium and a Science Exhibition. He is the reviewer in IEEE and other reputed Journals and has delivered special guest lecturers in many International and National conferences. He is an active member of IDDS and participated in different rural community development projects.

Modisa Mosalaosi received his Bachelor of Science in Electrical Engineering in the year 2009, MSc Eng. and PhD degrees in Electronic Engineering in the year 2015 and 2017 respectively, all from the University of KwaZulu-Natal, Durban, South Africa. He is currently a Lecturer at the Botswana International University of Science and Technology (BIUST). His research interests include, power line communication, RF and Microwave propagation, free space optics and green power technologies. Mosalaosi is a member of IEEE and IEEE-HKN Mu Eta Chapter. 